XX.- Supplement to the Lower Devonian Fishes of Gemünden. By R. H. Traquair, M.D., LL.D., F.R.S., Kieper of the Natural History Collections in the Royal Scottish Mluseum, Edinburgh. (With Three Plittes.)

(Read Dיumber 19, 1904. Given in for publieation April 14, 1905. Issued separately May 13, 1905.)

Since the publication, about a year ago, in the Transactions of this Society, of my paper on the Lower Devonian Fishes of Gemünden, ${ }^{*}$ a review of it has appeared in the pages of Science by Professor Bashford Dean, of New York. In this review Professor DEAN endeavoured to throw doubts on the correctness of my orientation of the elements of the dermal skeleton of Drepancespis Gemündenensis, in the following words : †-

"Thus, his grounds seem inadequate for distinguishing dorsal and ventral sides. In no specimen figured is the relation of the dorsal lobe of the tail shown convincingly to be continuous with the so-called dorsal aspect; moreover, the eyes occur on the side which TRaquaIR regards as ventral. Unless additional evidence is forthcoming, it would accordingly seem to me more probable that the 'labial' $\ddagger$ of TRAQUAIR was the 'rostral' plate, a structure which appears constant in Heterostracans. This interpretation would permit the eyes to be seen at the sides of the dorsal armoring, as indeed they occur in Pteraspis, and would enable us at the same time to locate the greater number of the larger plates on the dorsal side. This conclusion is the more satisfactory on comparative grounds, since there is not an instance in the chordate phylum in which the eyes and the most complete part of the armoring appear on the (morphological) ventral side. And I doubt whether, on the present evidence, we can assume, with Professor PatTen, that Diepanaspis might have evaded the law of vertebrate orientation by swimming on its back. Dr TraquaIR has attempted to solve this ronso-ventral difficulty by suggesting that either the orbits are 'sensory' pits, i.e. not orbits, or that, 'since the specimens are all crushed absolutely flat, it is by no means certain that in the original uncompressed condition the openings did not look out to the side."

The tail of Irepanaspis being heterocercal, the rorsil aspect of the caudal fin, in accordance with the universal condition of such trils among fishes, will be that along which the prolongation of the body-axis proceeds, as shown by its greater extent, by the squamation, and more especially by the larger size and (usually) greater number of the ridge scales or "fulcra." In the above-quoted criticism Professor Bashrord Dean gave it as his opinion that I had failed to prove that this dorsal aspect of the tail was coincident with that aspect of the carapace which I described as dorsal, and which he,

* "The Lower Devonian Fishes of Gemünden," T'rnl.. Rivy. Soc. Edin., vul. xl., Part iv., October 1903.

† Science, N.s., vol. xix., No. 471, January 8, 1904.

† The plate here meant is in my memoir termed mentul, and not "labial."

TRANS. ROY. SOC. EDIN., VOL. XLI. PART II. (NO. 20). 
from other reasons, thought much more likely to be ventral. In other words, I had turned the fish upside down.

It was, however, sutisfactory to read in the same periodical, in few months later, the following counter-eriticism by another eminent American palæichthyologist, Dr C. R. Eastman, of Cambridge, Massachusetts:-

"Whatever may be thought of TraquaIR's figures, though his Plate II. seems to us conclusive enough, there can be no question about the originals, and those who have examined them attentively are compelled to arlmit the correctness of the Scottish author's interpretations. The dorsal ridge-scales are lirger than the ventral and form a more extended series, beginning further forward and continuing further back than the ventral fulcra. Several specimens in the Edinburgh Museum have been pointed out to the present writer by Dr Traquarr in which this row of prominent ridge-scales can be traced continuously from a point shortly behind the median dorsal plate to the tip of the dorsal lobe of the tail. The extent to which the caudal lobes are covered with fulcra is well shown in Plate IV. and Plate I. fig. 1 of the memoir in question, and their connection with upper and lower systems of body-plates appears tolerably distinct." *

For my part, I certainly hold that the relations of the heterocercal tail to the two surfaces respectively of the carapace were quite satisfactorily proved in the plates plus text of my former paper. The great median plate of the surface on which the mouth and supposed orbits are placed, I described as being different from the one on the other side (see Plates I., II., and IV.) by being bilobate in front, and having behind a peculiar raiser longitudinal fold continuing the rirection of the posterior notch a little way forwards. It is true that I did not, among my plates, reproduce a photograph of an entire specimen of this plate, the one shown in Pl. III. being deficient posteriorly, but in the text-figure 3, p. 729, I " restored its contour from other specimens" (p. 728). And in the specimen, of which a good photograph is given, in Pl. V. fig. 1, the line of smaller fulcra, situated on the presumably ventral margin of the tail, is exhibited with absolute dearness rumning up to the posterior (cloacal) notch of that plate, which, as shown hy its prominent median fold, is as undoubtedly the plate described by me as ventral.

But as Professor Dean's remarks have been widely circulated in so well-known a periodical as Science, I shall in this "Supplement" go over the subject of the orientation of the exoskeleton of Liepancispis once more, this time illustrating by specimens not figured in my previous memoir, though one of them (Pl. I.) was before me when it was written.

The depressed and flattened carapace of Dirpanaspis shows in front a wide mouthslit, which, though nearly terminal, is not quite so, and consequently is seen only on one aspect of the creature, which may meanwhile be called the oral one. It 
is this aspect, represented in Pl. III. of my former memoir, which I have denoted "ventral," : $m$ m on which we find two median plates, the anterior and smaller of which bounds the mouth behind, while the larger one has posteriorly a conspicuous meelim notch (cloacal), the direction of which is continued forwards for some little distance in the middle line by the longitudinal fold to which I have already called attention. In this side of the creature are also seen the "orbital" or sensory plates, the anterior and posterior ventro-laterals, and a narrow external marginal portion of the postero-lateral on each side. In the specimen to which I have just referred the posterior extremity of the great median plate is deficient, but this deficiency I now remedy by figuring the one shown in Pl. I. of this Supplement, and I may say that this is the specimen which enabled me to complete the restoration of the plate in question, as seen in text-figure 3, p. 7:9 of my previous paper. Of this example an accurate photograph is given in $\mathrm{Pl}$. l. of the present communication, and on comparing this figure with Pl. III. (former paper) it will be at once seen that the creature presents to us the same oral surface; for though the front part with the mouth is lost, there is no mistaking the "orbital" of one side $(x)$, the anterior ventro-laterals (a.v.l.), the postero-laterals (p.l.), and the posterior ventro-lateral of one side. In the centre of the specimen we see the great median plate (m.r.) of this surface, considered by me as ventral, in a state of nearly absolute completeness, though obliquely deformed like the rest of the specimen. With perfect clearness we see the bilobate front of this plate, the re-entering angle thereby formed being occupied by a portion of the mental plate $(m$.$) , while posteriorly the median fold, terminating on the notch behind, is shown$ with absolute distinctness. Then, below this, the hinder portion of the median plate (m.d.) of the opposite side is seen from its inner or visceral aspect, being brought into view by an oblique backward thrust.

The aspect of the carapace to which the last-mentioned plate (m.r.) belongs is seen in Plates I. and II. of my former memoir. On it the mouth-slit is never visible, and consequently the term aboval may be temporarily applied to it. It shows only one large median plate, which differs strikingly from the corresponding one on the oral aspect in its proportionally narrower shape, in not being emarginate or bilobate in front, in having its posterior notch smaller, pointed in front and filled up by a narrow plate, and finally in the total absence of the median fold which is so conspicuous on the posterior part of the great median plate of the oral surface. We also recognise the aboral surface by the much greater extent to which the postero-lateral plates are visible, by the greater number of small polyoral plates surrounding the median one, by the fusion of some of these little plates into what I have called the rostral plates in front, and by the two shallow pits, one on each side of the front of the head, caused by the compression of one of the small plates over the ring-like thickening round the margin of the orbital or sensory opening internally.

Having now made sure of the two surfaces of the carapace, the details of which are put together in my restored figures (pp. 726 and 729 of my previous memoir), it now 
remains to settle accurately the relation to those surfaces of the two margins of the caudal fin.

In fig. 2, Pl. V. of my previous paper, a tail is represented which, though truncated behind, shows clearly that on one margin the fulcral scales are much larger than on the other; and an additional difference is, that those of the smaller series are, in front, peculiarly short and erect. Then, an inspection of fig. 1, Pl. II. of the present Supplement shows that the caudal fin, though not bilobate, is unsymmetrical above and below, and projects further back on that aspect on which the larger fulcra are placed; moreover, we observe that the lateral scales which clothe the fin are, under the line of larger fulcra, also larger. In other words we have, to all appearance, a normal piscine heterocercal tail, of which the longer margin, provided with the larger fulcra, is presumably the dorsal one, and it now remains to prove with which aspect of the carapace this margin of the tail coincides. This question, I maintain, was already settled by the specimen represented in Pl. V. fig. 1 of my previous memoir, in which the line of smaller fulcra is traceable to the apparent cloacal opening at the posterior extremity of the median fold of that plate, which is certainly the median plate of the oral aspect of the carapace.

But a still more complete demonstration of these relations is afforded in Pl. III. of the present Supplement. Here we have a specimen seen from the oral side, as shown by the form of median plate ( $m . v$.) with its posterior fold, the presence of the sensory plate $x$. with its orbital (?) perforation, and of the plates a.v.l. and p.v.l., designated by me anterior and posterio ventro-lateral respectively. It may also be noted that the median plate (m.d.) of the aboral side, seen from the internal surface, is shown displaced, and projecting from below the root of the tail. A considerable part of the caudal fin with the fulcra on both margins is shown, and, with absolute clearness, the line of smaller fulcra $(v, f$.$) is seen to proceed forwards and end at the posterior extremity of$ the great median plate of the oral surface of the carapace. Compare this figure with the two in $\mathrm{Pl}$. V. of my former memoir.

It is therefore proved, beyond all possibility of doubt, that that margin of the caudal fin which carries the row of smaller fulcra is coincident with the oral aspect of the carapace; and conversely, that the other margin, which projects further back, carries the large fulcra, and presumably contained the caudal body-prolongation, is coincident with the aboral one. If, then, the tail is constructed arcording to the normal piscine heterocercal type, the aboral surface of the carapace is the dorsal, and the oral one is the ventral surface.

But it may be asked whether in Dirpanaspis the heterocercy might not have been reversed as in the reptilian Ichthyosaum, by the caudal prolongation of the body axis having passed down along the ventral margin of the ciuclal fin, insteal of along the dorsal one. In that case I should still be in the wrong as regards the orientation of the two surfaces of the carapace!

In the first place, we know of no such case among fishes. For, though the lower 
lobe of the caudal fin in the Angel-fish (Squatina) is larger and projects further back than the dowsial one, there is no downward bend of the vertebral axis, which proceeds straight backwards. Nor has the greater size of the lower caudal fin lobe in the teleostean homocercal Flying-fish (Exoccetus) any bearing on the ruestion.

Another circumstance which cannot be overlooked is the position of the mouth. This, as I have alrearly shown, is not truly terminal, but is situated on that aspect of the carapace which is coincident with the shorter margin of the fin and the apparent cloacal opening. Now, although the mouth may appear to look upwarls in such a peculinrly specialised bony fish as the recent Angler (Lophius), yet, judging from the analogy of other Ostracoderm types, such as Pteraspis, Cephalaspis, and Asterolepis, the dorsal side is not the one on which we would expect to find it in the case of Drepanaspis.

But of really crucial importance is the position of the cloacal opening or vent. It, at least, we cannot expect to find on the dorsal aspect of the tail of a fish or fish-like vertebrate, unless we should take upon ourselves to deny the presence of a notochordal vertebral axis in those creatures. Now if we look at Pl. II. of my former memoir, which represents the aboral surface of the fish, we find no trace of any such opening, although the scales of the middle line, between the posterior margin of the great median plate and the fulcra of the tail, are in complete order and well preserved. The aboral side of the fish is therefore not ventral; and if it be not ventral, then it is dorsal, and the oral side is the ventral one, in accordance with my original description.

Turning now to this oral side,-in the specimen represented in fig. 1, Pl. V. of my former memoir, the position of the cloacal opening seems to me to be distinctly marked just in the notch which follows the prominent posterior median fold of the great central plate, in front of the first fulcral scale in the middle line. Again, in the specimen represented in Pl. III. of the present Supplement, we have the great median plate (m.v.) of the aboral surface distinctly shown, as is also its median fold behind and the notch $c$., though one margin of the latter is broken away. It is this notch $c$. which, in my opinion, marks the position of the cloacal opening, in perfect accordance with the appearances shown in the figure just referred to, and also represented in the restoration of the ventral surface in text-figure 3, p. 729 of my previous memoir. It is, however, to be noted that in this specimen (Pl. III.) the anterior extremity of the first (ventral) fulcral scale is slightly displaced, or shoved to one side, so that it no longer closes the cloacal notch (c.), which is consequently left open behind.

I submit, therefore, that I have amply shown-

First. - That the alowal aspect of the carapace of Drepanaspis is coincident with the apparent dorsal "lobe" or aspect of the caudal fin.

Second.-That the absence of a cloacal opening on the aboral aspect of the commencement of the tail, and its apparent presence on the oral one, is equivalent to a proof that the aboral margin of the tail, consequently of the entire creature, is the dorsal aspect. Conversely, the oral aspect is the ventral ; and my previous orientation 
of the creature is correct, no matter on which side of it the openings supposed to be orbits are placed.

No one will question the sensory nature of these openings, but that they really are eye-orbits, however possible or even probable that may be, is by no means certain. Their position is, however, analogous to that of the supposerl orbits in Pteraspis; and I can only repeat that, situiterl as they are so near to the right and left edges of the vertically flattened carapace, they might well, in the living and uncompressed condition of the animal, have enjoyed a considerable amount of lateral outlook.

Scales of the tail-pedicle.-I have already in my previous memoir (p. 731) alluded to the fact that on that part of the tail which lies between the carapace and the caudal fin there is at least one longitudinal row of scales, which are considerably higher than broad, and which are seldom well seen, owing to that part being usually obscured by pyritous deposit. As the form of these scales can only be expressed in a direct lateral view, they could not be properly represented in my restored figures, in which the tailpedicle is depicted as seen from above and from below.

However, in fig. 2, Pl. II. of this Supplement the tail-pedicle is seen free of pyrites, and here two rows of such rertically elongated scales are clearly visible. At the caudal fin they pass into smaller scales of a rhombic form, which become very small on the fin-membrane.

This specimen is also interesting in this respect, that, while lying on its ventral surface, that is to sily, back upwards, the median dorsal plate has dropped out and the visceral aspect of the median ventral one has come into view, this plate being at once recognisable by the prominent emargination of its anterior border. This condition is the reverse of what more commonly occurs, for, as I have already stated, it is not at all rare to find in a specimen lying on its back that the median rentral plate has been lost, and the inner surface of the median dorsal one shown in consequence. See my previous memoir, Pl. IV., and explanation, p. 738.

In conclusion, I may remark that up to the present I have not been able to find in Drepanaspis any trace of a lateral sensory canal system. 


\section{EXPIANATION OF THE I'LATES.}

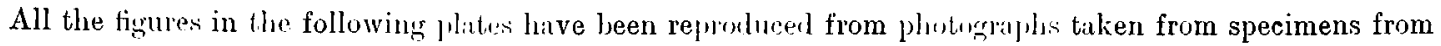

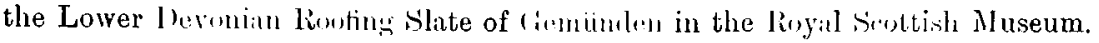

$$
\begin{aligned}
& \text { m.d., midian llonsis plate. } \\
& \text { m.r., median ventral. } \\
& \text { m., mental. } \\
& \therefore, \text { sensery. } \\
& \text { a.i.l., anterior ventro-lateral. } \\
& \text { 1. } \% \text {., posterior ventm-lateral. }
\end{aligned}
$$

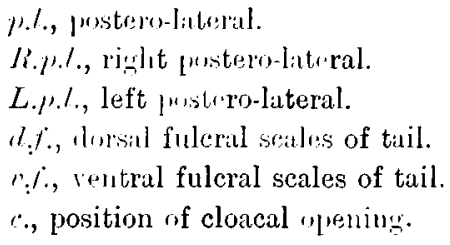

Plate ].

Ventral surface of a carapace of Lropenuspis Gemïulenensis, smmewhin deficient in front and in the left side. The specimen is strongly obliquely deformed, so that the lateral plites on the right side are shoved in adrance of those on the left. Here we have an exceedingly goml view of the median ventral plate (m.v.) with its posterior median fold and notch, and the anterior emargination in which the hinder portion of the mental plate $(\mathrm{m}$.$) is seen to be lorlyed. Owing to oblique displacement of parts, the hinder portion of the$ internal surface of the median dorsal plate (m.d.) is also seen below and behind the median ventral. Compare this figure with that on Plate III. of my previons memoir.

\section{Plate II.}

Fig. 1. Tail and caudal fin of Irepmaspis, to show the oblique heterocercal configuration, and the greater size and strength of the fulcra on the upper or dorsal margin. The lateral scales of the tail-pedicle in front of the caudal lin are covered with pyritous deposit, and the commencement of the row of dorsal fulcra is also not exhihited. Natural size.

Fig. 2. Fiecimen of Dreprencesis somewhat deficient on the left side, lying on its ventral surface, but with the median dorsal plate wanting, so that the inner surface of the median ventral is exposed. At the antero-external corner of the carapace the small rounded pit formed by the compression of one of the external dorsal polygonal plates over the internal ring-like thickening of the upening in the sensory plate is well marked; behind this, the outer margin of the carapace and its postero-lateral angle are formed by the postero-lateral plate. The median row of dorsal fulcra is seen from its commencement, and the two rows of vertically elongated scales on the side of the tail-pedicle are unusually well shown. The ventral fulcra are not seen, having been cut off by the broken edge of the stone, but a great part uf the expanse of the caudal fin, covered with small rhombic scales, is visible. One-half natural size.

\section{Plate III.}

Specimen of Drepanaspis crmümlemensis lying on its lack, and showing the rreater part of the outer surface of the median ventral plate (m.r.) with the posterior median fold, and the notch $r$. marking the position of the cloacal opening. This notch is followed by the line of median ventral fulcral scales $(v \cdot \dot{f})$, the first of which is slightly displaced in front, so that its anterior margin no longer completes, as it ought, the notch into an opening. The dorsal fulcra $(l, f)$, of obviously larger size, are seen on the opposite sille of the tail, the anterior ines being slightly confused. The scales of the begimning of the tail-pedicle are, as is commonly the case, obscured hy pyritous deposit, but those further back and on the caudal fin are clearly exhibited. Portions of the left sensory plate (.r.), of the left anterior ventro-lateral (a.v.l.), and of the left postero-lateral $(L . p . l$.$) are seen at the top of the figure; a portion of the right postero-lateral (R.p.l.) is also$ seen below, removed from the rest of the fish, and turned right over so as to show its dorsal surface. Lastly, the median dorsal plate $(m . l$.) is so displaced from the rest of the body as to be seen almost in its entirety, - seen, of course, from its internal or visceral aspect. 
Dr R. H. Traquatr on Fossil Fishes of Gemuenden, Supplement-Plate I.

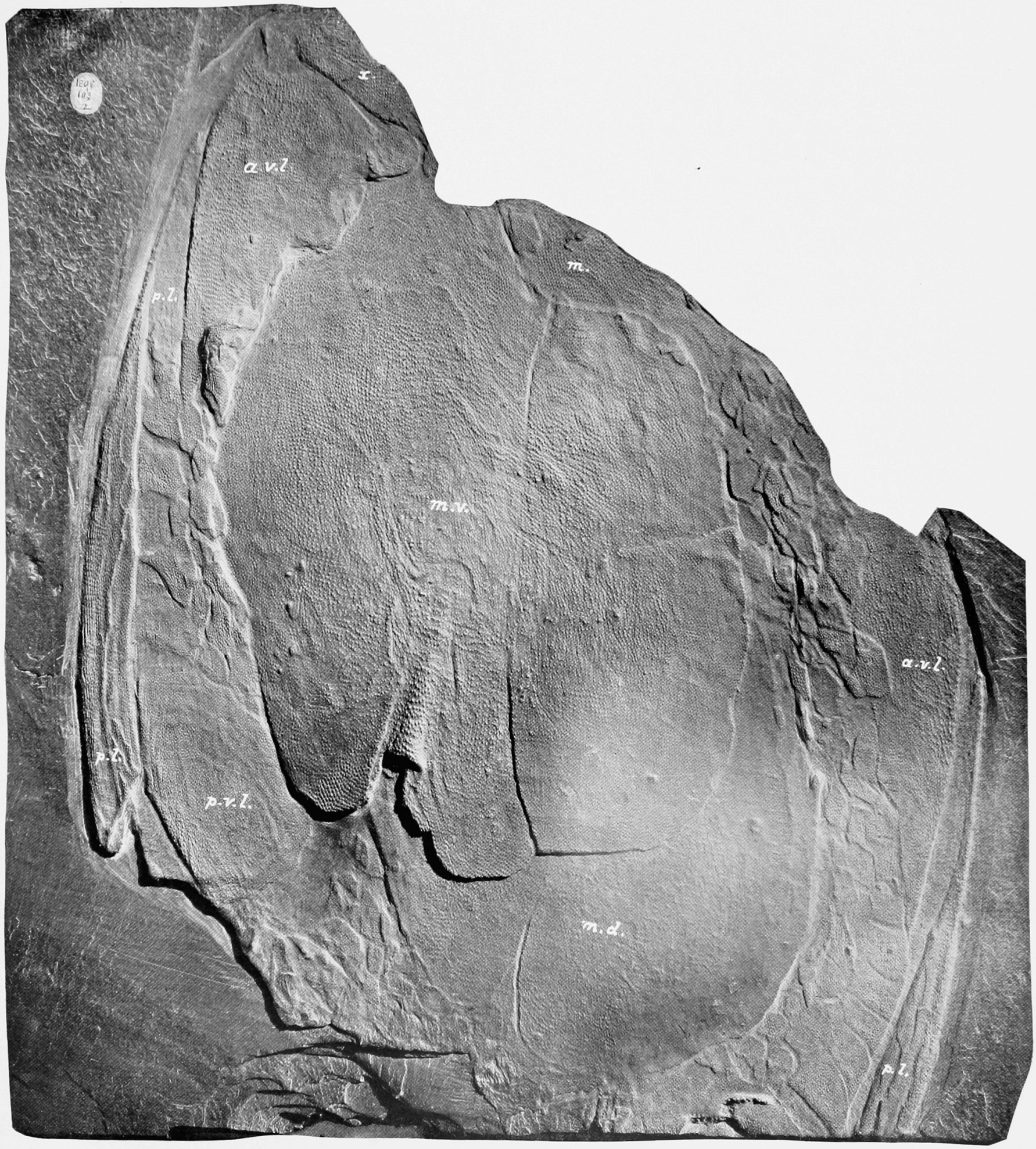

Reduced by One-fourth. 
Trans. Roy. Soc. Edin r.

Vol. XLI.

Dr R. H. Traquatr on Fossil Fishes of Gemuenden, Supplement-Plate II

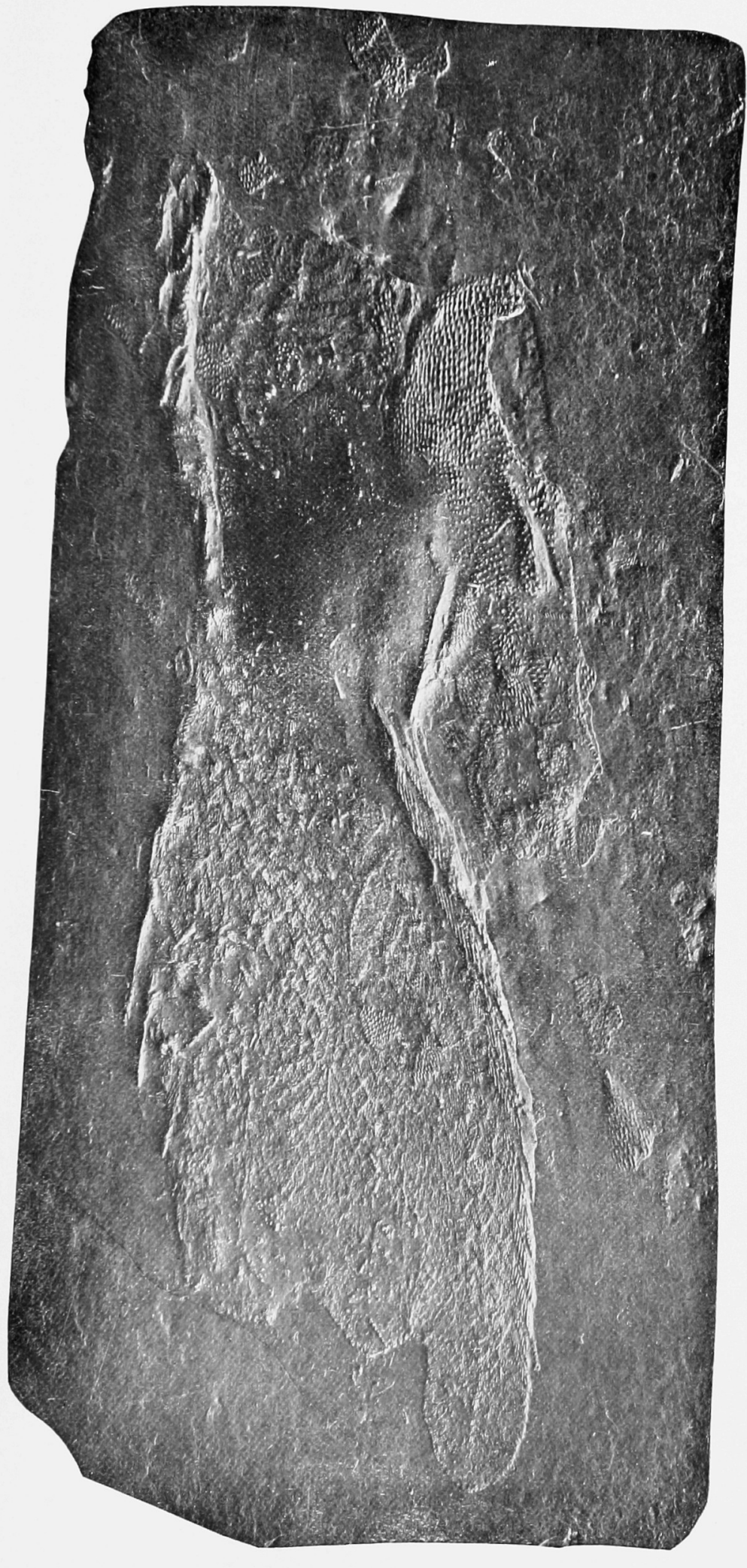

Fig. 1.

Natural Size.

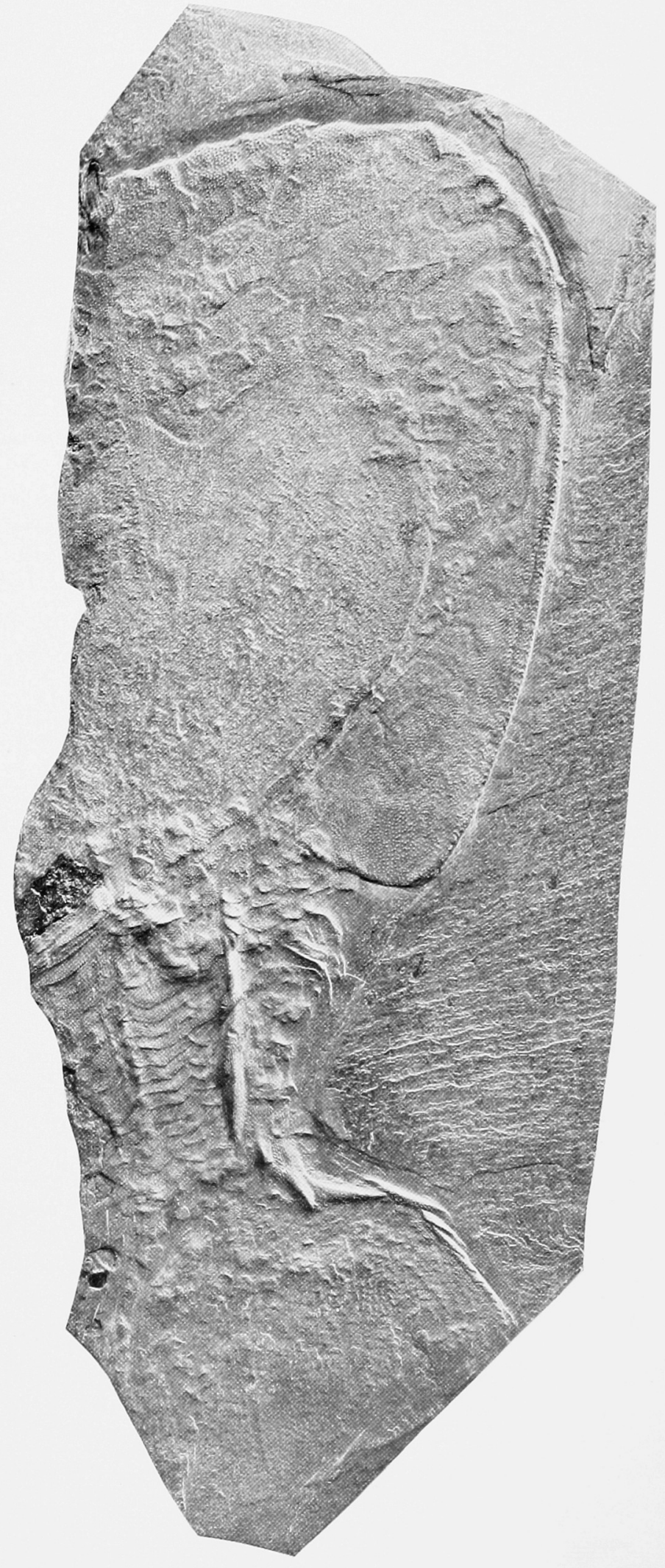

Fig. 2. 
Dr R. H. Traquatr on Fossil Fishes of Gemuenden, Supplement-Plate ili.

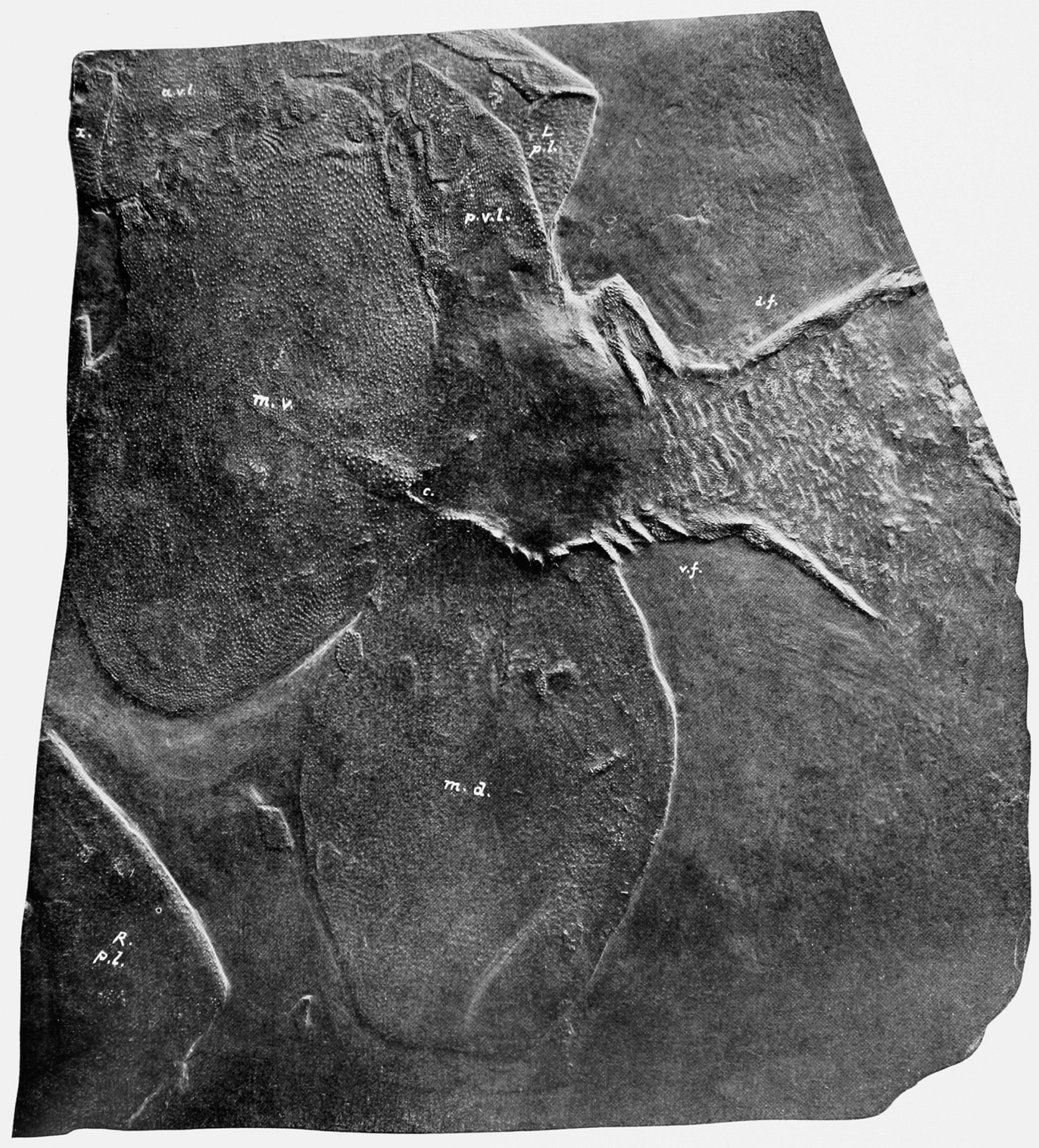

Reduced by Two-sevenths. 